\title{
Syringe pump displacement alters line internal pressure and flow
}

\author{
[Le déplacement verticalde la pompe à perfusion modifie la pression interne du \\ cathéter et le débit]
}

Hiroshi Igarashi MD, ${ }^{*}$ Yukako Obata MD, ${ }^{*}$ Yoshiki Nakajima MD PhD, ${ }^{*}$ Takasumi Katoh MD PhD, ${ }^{*}$ Koji Morita PhD, $†$ Shigehito Sato MD PhD*

Purpose: It has been reported that the actual flow from a syringe pump changes due to vertical movement of the pump in vitro, but a direct study of the in vivo effects of fluid delivery irregularities caused by vertical pump displacement has not been performed. The aim of this study was to assess the influence of positional changes of the syringe pump on the internal pressure (IP) and flow from the circuit, and to examine blood pressure changes caused by pump movement in animals with or without hemorrhagic shock.

Methods: To simulate clinical conditions, we used a rabbit model. We first measured the changes in line IP and flow from the syringe pump after moving the pump $50 \mathrm{~cm}$ vertically upwards or downwards. With the same animal, we then recorded the blood pressure changes under these conditions during norepinephrine (NE) infusion, using a rabbit hemorrhagic shock (HS) model.

Results: Following downward movement of the syringe pump, the IP increased by $37.5 \pm 4.0 \mathrm{mmHg}$ and IP decreased by $37.3 \pm 3.1$ $\mathrm{mmHg}$ following upward movement of the syringe pump. In the rabbit HS model, movement downwards decreased systolic blood pressure (SBP) by $-17 \pm 6.9 \%(P<0.001)$, while upward movement raised SBP by $45.7 \pm 21.5 \%(P<0.001)$ from baseline values.

Conclusions: Vertical displacement of the syringe pump alters the flow due to a change of line IP, and blood pressure can be affected by pump movement during NE infusion.

Objectif: On sait que le débit effectif dans la pompe à perfusion change avec le déplacement vertical de la pompe in vitro, mais aucune étude directe n'a été réalisée sur les effets in vivo de l'irrégularité du débit causée par le déplacement vertical de la pompe. Nous voulions évaluer l'influence des changements de position de la pompe à perfusion sur la pression interne (PI) et le débit provenant du circuit, et vérifier les changements de tension artérielle causés par le déplacement de la pompe chez des animaux soumis ou non à un choc hémorragique.

Méthode : Pour simuler les conditions cliniques, nous avons utilisé un modèle expérimental chez un lapin. Nous avons d'abord mesuré les changements de Pl, dans le cathéter, et de débit provenant de la pompe à perfusion après avoir déplacé la pompe de $50 \mathrm{~cm}$ vers le haut ou vers le bas. Nous avons ensuite enregistré les modifications de tension artérielle dans ces conditions pendant la perfusion de norépinéphrine (NE) en utilisant un modèle de choc hémorragique $(\mathrm{CH})$.

Résultats : Après le déplacement de la pompe vers le bas, la $\mathrm{PI}$ a augmenté de 37,5 \pm 4,0 mmHg, mais la Pl a baissé de 37,3 \pm 3,I $\mathrm{mmHg}$ après le déplacement vers le haut. Dans le cas du modèle de $\mathrm{CH}$ chez le lapin, le déplacement vers le bas a fait baisser la tension artérielle systolique (TAS) de $-17 \pm 6,9 \%(P<0,001)$, tandis que le déplacement vers le haut a fait monter la TAS de 45,7 $\pm 21,5 \%$ $(P<0,001)$ par rapport aux valeurs de départ.

Conclusion : Le déplacement vertical de la pompe à perfusion modifie le débit en raison d'un changement de la PI du cathéter. La tension artérielle peut être modifiée par le mouvement de la pompe pendant la perfusion de NE.

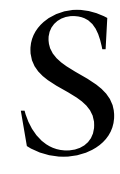

YRINGE pumps are essential devices for critically ill patients who require continuous infusion of vasopressors or vasodilators. Most clinicians believe that the pump correctly and uniformly delivers fluid because it is computer-controlled. However, several reports suggest that flow output from syringe pumps may change

From the Department of Anesthesiology and Intensive Care, ${ }^{*}$ and the Surgical Center, $†$ Hamamatsu University School of Medicine, Hamamatsu, Japan.

Address correspondence to: Dr. Hiroshi Igarashi, Anesthesiology and Intensive Care, Hamamatsu University School of Medicine, 1-20-1

Handayama, Hamamatsu, 431-3192, Japan. Phone and Fax: +81-53-435-2284; E-mail: igaiga@hama-med.ac.jp

Support was provided solely from department sources.

Accepted for publication January 28, 2005.

Revision accepted March 29, 2005. 
unintentionally under certain circumstances. For example, it has been shown that moving the syringe pump downwards reduces the amount of drug delivered, ${ }^{1}$ and that during downward displacement of syringe pumps, flow is interrupted temporarily due to retrograde aspiration. ${ }^{2}$ After cardiac surgery, a simple maneuver, such as lifting the patient off the operating table, can cause dysrhythmias and marked blood pressure variations if the patients are receiving vasoactive drugs. ${ }^{3}$ We speculate that these observations may be due, in part, to a change of flow caused by vertical displacement of the syringe pump. ${ }^{1,2}$

These studies were performed using in vitro models, but no data have verified changes of the line internal pressure (IP). Furthermore, the in vivo effects on blood pressure associated with fluid delivery irregularities due to vertical pump displacement are unknown. Hence, the aim of this study was to assess the influence of positional changes on the syringe pump equipped for measurement of line IP and flow. The clinical impact on blood pressure changes during norepinephrine (NE) infusion in animals with or without hemorrhagic shock was also evaluated.

\section{Methods}

The study protocol was approved by the Institutional Animal Care and Use Committee of Hamamatsu University School of Medicine.

The study was performed using a syringe pump (IVAC® Syringe Pump P7000, ALARIS Medical Systems Inc., Hampshire, UK) equipped in such a way that the IP of the infusion circuit could be measured. To simulate clinical conditions, we used rabbits fitted with $i v$ infusion lines connected to the syringe pump. We first measured changes in the flow when the syringe pump was raised or lowered vertically. We then observed the hemodynamic changes occurring during movement of the syringe pump while administering $\mathrm{NE}$ in a rabbit hemorrhagic shock model.

The experimental set up is shown in Figure 1. Seventeen Japanese white rabbits weighing between 2 and $2.5 \mathrm{~kg}$ were used in the study. The animals were first anesthetized with diethyl ether and a catheter (24 G, Insite ${ }^{\mathrm{TM}}$, Becton Dickinson ${ }^{\circledR}$, UT, USA) was then positioned in the superficial vein in the ear of each animal to facilitate drug administration. Following tracheotomy, the animals were mechanically ventilated (Shinano®), respirator model SN-480-5, Shinano Manufacturing Co. Ltd., Tokyo, Japan) with a tidal volume of $30 \mathrm{~mL}$ at a frequency of 40 to $60 \mathrm{~min}^{-1}$. Ventilation was managed such that $\mathrm{PaCO}_{2}$ was maintained between 30 and $40 \mathrm{mmHg}$. Pentobarbital $(25$ $\mathrm{mg} \cdot \mathrm{kg}^{-1} \cdot \mathrm{hr}^{-1}$ ) was continuously administered through the superficial vein in the ear, and pancuronium bromide (initially $0.5 \mathrm{mg} \cdot \mathrm{kg}^{-1}$ and then $0.2 \mathrm{mg} \cdot \mathrm{kg}^{-1} \cdot \mathrm{hr}^{-1}$ ) was administered $i v$ from the syringe pump, placed at the same elevation as the animals. To facilitate the experiments, catheters $\left(22 \mathrm{G}, 23 \mathrm{~mm}\right.$, Serflow ${ }^{\mathrm{TM}}$, Terumo ${ }^{\circledR}$, Tokyo, Japan) were placed in the femoral vein and artery for blood pressure monitoring and blood sampling, respectively. The arterial blood pressure and electrocardiogram (lead II) were monitored continuously. Ringer's solution was administered at 7 $\mathrm{mL} \cdot \mathrm{kg}^{-1} \cdot \mathrm{hr}^{-1}$ for fluid replacement.

To prevent coagulation of blood, we administered heparin $i v\left(1000 \mathrm{U} \cdot \mathrm{kg}^{-1}\right)$, and then connected the circuit system to the catheter inserted in the femoral vein of the animal. The body temperature of the animals was monitored using a rectal probe (RET- $2^{\mathrm{TM}}, \mathrm{AD}$ Instruments ${ }^{\circledR}$, Grand Junction, CO, USA) and was maintained at 36 to $37^{\circ} \mathrm{C}$ by wrapping the animals in vinyl covers.

The syringe pump (IVAC® Syringe Pump P7000, ALARIS Medical Systems, Inc., Hampshire, UK) used in the study has a sensor that can measure IP of the circuit. With a "special extension tube" (SET) including an in-line chamber to which the transducer was attached (IVAC@ Solution Administration Set, Kawasumi ${ }^{\circledR}$, Tokyo, Japan), it can measure the IP of the circuit of the syringe pump continuously. Since it does not allow measurements below atmospheric pressure, we placed another transducer (Baxter ${ }^{\mathrm{TM}}$, Uniflow ${ }^{\circledR}$, Edwards Lifesciences LLC, Irvine, CA, USA) into the circuit to obtain data below this pressure. The transducer system was calibrated with one point calibration at atmospheric pressure. Data were recorded on a personal computer and analyzed using the Power Lab system ${ }^{\mathrm{TM}}$ (AD Instruments ${ }^{\circledR}$, Grand Junction, CO, USA). Data of both positive and negative pressures were recorded with this system.

The infusion circuit system consisted of a $20 \mathrm{~mL}$ syringe (Terumo®, Tokyo, Japan), one SET, two extension tubes $(1.0 \mathrm{~mm}$ internal diameter, $500 \mathrm{~mm}$ length, Hakko®, Tokyo, Japan) which we generally use in the operating room, and two three-way stopcocks (Terumo®, Tokyo, Japan), which were placed between the SET and the Hakko ${ }^{\circledR}$ extension tube, and between the two Hakko ${ }^{\circledR}$ extension tubes, respectively. This infusion system was connected to the catheter that was placed in the femoral vein. An outline of the experiments is shown in Figure 1, and are described in detail below.

\section{Experiment 1}

In experiment 1 , we investigated the changes in line IP and flow from the syringe pump when the pump was 
TABLE I Changes in line internal pressure (IP)

\begin{tabular}{lll}
\hline Movement & Downward & Upward \\
\hline Changes in line IP $(\mathrm{mmHg})$ & & \\
Flow & & \\
$1 \mathrm{~mL} \cdot \mathrm{hr}^{-1}$ & $37.4 \pm 2.6$ & $-3.7 \pm 2.8$ \\
$3 \mathrm{~mL} \cdot \mathrm{hr}^{-1}$ & $37.5 \pm 4.2$ & $-37.2 \pm 2.6$ \\
$10 \mathrm{~mL} \cdot \mathrm{hr}^{-1}$ & $37.8 \pm 5.1$ & $-37.7 \pm 3.9$ \\
Total & $37.5 \pm 4.0$ & $-37.3 \pm 3.1$ \\
\hline
\end{tabular}

Mean $\pm \mathrm{SD} ; n=17$. There were no significant differences between downward and upward displacements.

TABLE II Zero drug delivery time (ZDDT) and back flow volume (BFV)

\begin{tabular}{llll}
\hline Infusion rate & $1 \mathrm{~mL} \cdot \mathrm{hr} r^{-1}$ & $3 \mathrm{~mL} \cdot h r^{-1}$ & $10 \mathrm{~mL} \cdot b r^{-1}$ \\
\hline ZDDT $(\mathrm{sec})$ & $217 \pm 44.1^{*}$ & $56.8 \pm 13.4^{*}$ & $15.3 \pm 3.8^{*}$ \\
$\mathrm{BFV}(\mu \mathrm{L})$ & $12.3 \pm 4.1$ & $14.0 \pm 3.8$ & $21.1 \pm 3.5$ \\
\hline
\end{tabular}

Mean $\pm S D ; n=17 .{ }^{*} P<0.001$ between settings.

moved upwards or downwards. In order to study the effect of changes in elevation, we injected a small oil bubble into the horizontal part of the extension tube through the three-way stopcock, and measured the distance that the bubble moved (Figure 1). Initially, the elevation of the pump was the same as that of the animal (the baseline elevation). Before any pump movements were made, the pump ran for ten minutes to allow stabilization. The pump was then quickly moved $50 \mathrm{~cm}$ downwards vertically, and the flow was recorded. Five minutes after pump movement, we slowly returned the pump to the baseline elevation. After a ten-minute stabilization period, the pump was moved $50 \mathrm{~cm}$ upwards from the baseline, and the flow was recorded. In this manner, the change in flow was measured based upon the distance of oil bubble movement after each syringe pump movement. The changes in flow from the syringe pump were investigated for three groups with three different syringe pump settings: 1 $\mathrm{mL} \cdot \mathrm{hr}^{-1}, 3 \mathrm{~mL} \cdot \mathrm{hr}^{-1}, 10 \mathrm{~mL} \cdot \mathrm{hr}^{-1}$.

To evaluate the changes in delivery rate for downward pump displacement, the duration of the zerodrug delivery time (ZDDT; ${ }^{2}$ the period from the time the syringe pump was lowered to the time when the oil bubble returned to its initial position) was measured, and the back flow volume (BFV; the volume that backed up during the five seconds immediately after downward syringe movement plus the scheduled injection volume for five seconds) was calculated using the measured time and the distance of oil bubble movement. Similarly, the excess flow volume (EFV; the volume injected during the five seconds immediately after upward syringe movement minus the scheduled injection volume for five seconds) was calculated from oil bubble movement following upward syringe pump movement.

\section{Experiment 2}

After experiment $\mathrm{l}$ was completed for each animal, hemorrhagic shock was induced in the same animal. Following bleeding a volume of $25 \mathrm{~mL} \cdot \mathrm{kg}^{-1}, \mathrm{NE}$ administration was begun at $3 \mu \mathrm{g} \cdot \mathrm{kg}^{-1} \cdot \mathrm{min}^{-1}$ (at a rate of $\left.3 \mathrm{~mL} \cdot \mathrm{hr}^{-1}\right)$. At this setting, NE concentrations in the infusing fluid ranged from 0.12 to $0.15 \mathrm{mg} \cdot \mathrm{mL}^{-1}$. After confirming that the blood pressure had stabilized, the infusion pump was quickly moved downwards $50 \mathrm{~cm}$. After observation for five minutes, the syringe pump was then returned to baseline level. Five minutes later, the pump was elevated $50 \mathrm{~cm}$, followed by an additional five-minute observation period. To evaluate the hemodynamic changes, the percentage response (\%R) of the systolic blood pressure (SBP) were calculated, as follows: ${ }^{4}$

$\% \mathrm{R}$ of $\mathrm{SBP}=($ maximal or minimal value of SBP after syringe movement - SBP before syringe movement $) \times(\text { SBP before syringe movement })^{-1}$.

\section{Statistical analysis}

In experiment 1 , changes in flow in response to syringe pump movement at each flow setting were compared by analysis of variance (ANOVA), with post hoc adjustment of $P$ values. In experiment 2 , mean values (\%R of SBP) and standard deviations were calculated, and a Student $t$ test was used to determine the statistical significance of values before and after movement. A $P$ value $<0.05$ was considered statistically significant. All analyses were performed using Statistical Analysis Software, Stat View ${ }^{\mathrm{TM}} 5$ (SAS Institute Inc., Cary, NC, USA).

\section{Results}

\section{Experiment 1}

Changes in line IP are shown in Table I and Figure 4. Absolute changes were similar for both directions of movement, regardless of the infusion rate setting. Distances of oil bubble movement when the syringe pump was lowered or raised at each infusion rate setting are shown in Figures 2 and 3. Changes in ZDDT and BFV are presented in Table II. The ZDDT in each flow rate group was significantly different, compared to the two other groups $(P<0.001)$, but the BFV values were not significantly different betweem the groups. Similarly, EFV values were similar in each group. EFV values were $9.7 \pm 6.9 \mu \mathrm{L}$ in the $1 \mathrm{~mL} \cdot \mathrm{hr}^{-1}$ 


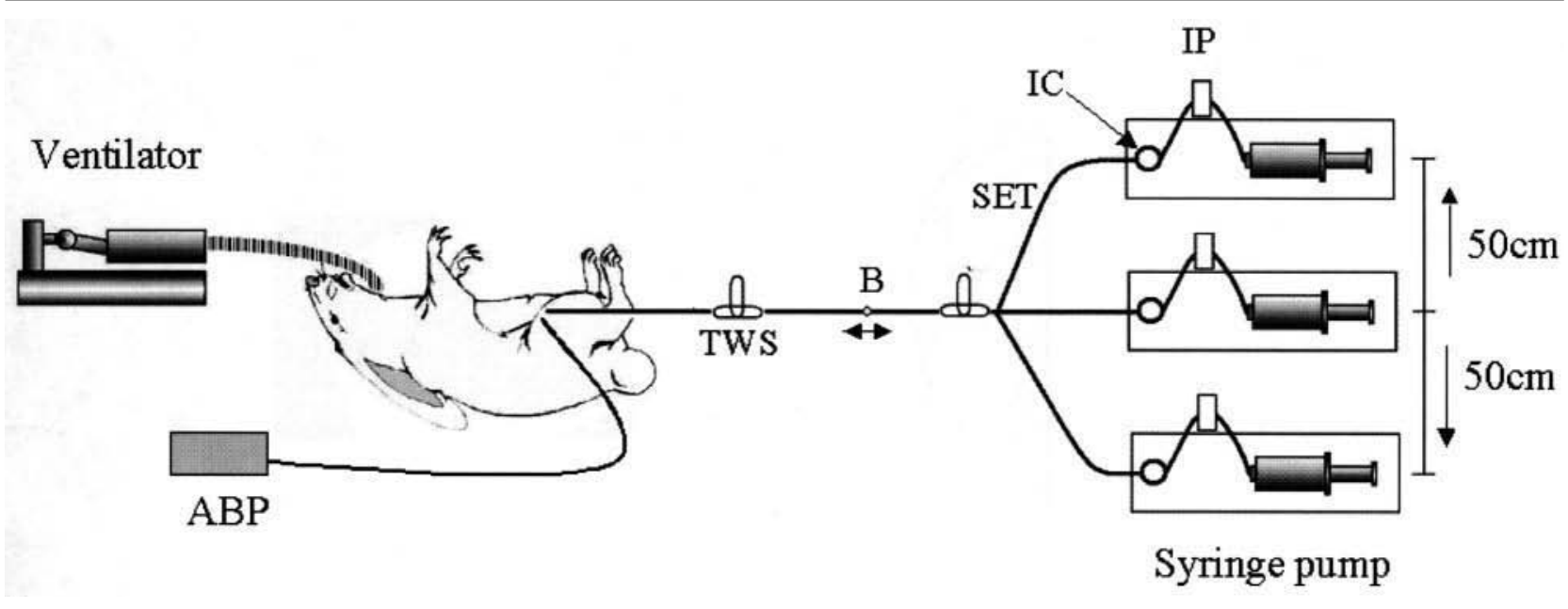

FIGURE 1 Experimental schemes. $\mathrm{ABP}=$ arterial blood pressure; TWS = three-way stopcock; $\mathrm{B}=$ oil bubble; SET = special extension tube; IC = in-line chamber of special extension tube to which the transducer is attached; IP: internal pressure of the circuit (another transducer attached in the circuit to obtain data of both positive and negative pressures).

group, $11.6 \pm 5.5 \mu \mathrm{L}$ in the $3 \mathrm{~mL} \cdot \mathrm{hr}^{-1}$ group, and $11.5 \pm 5.3 \mu \mathrm{L}$ in the $10 \mathrm{~mL} \cdot \mathrm{hr}^{-1}$ group.

\section{Experiment 2}

Using our model, the percent change of SBP in response to downward displacement was $-17 \pm 6.9 \%$ $(P<0.001)$. In response to upward displacement, the percent change was $45.7 \pm 21.5 \%(P<0.001)$.

An example of the changes observed in the hemodynamics and IP of the infusion circuit is shown in Figure 4. When the pump was lowered $50 \mathrm{~cm}$ from the baseline, line IP increased from 0 to $37 \mathrm{mmHg}$, and about 20 to $30 \mathrm{sec}$ later, the blood pressure decreased transiently. Conversely, when the pump was raised $50 \mathrm{~cm}$ from baseline, the line IP decreased to $37 \mathrm{mmHg}$, and the blood pressure increased rapidly.

\section{Discussion}

In this study, we investigated the influence of hydrostatic pressure on line IP and flow from a syringe pump. As hypothesized, the IP showed a significant increase upon downward pump movement, and a significant decline following upward pump movement. Changes in line IP affect pump flow and blood pressure during NE infusion, as also described elsewhere. ${ }^{1,2}$

We believe that it is important to monitor the IP of syringe pumps, especially for patients who are critically ill. In experiment 1 , the actual flow from the syringe pump increased transiently when the pump was raised, and decreased when the pump was lowered. The period from the moment the syringe pump was elevated or lowered to the time when the injection restarted (ZDDT) was also longer at a lower infusion rate. On the other hand, BFV and EFV did not show any significant differences between groups. In experiment 2 , both raising and lowering the syringe pump caused a significant change in the SBP in a rabbit hemorrhagic shock model. Clinically, these results suggest that a positional change of a syringe pump during infusion of catecholamines can affect the hemodynamics of a patient, and this may be particularly important in hemodynamically unstable patients.

On such occasions, the syringe pumps are usually placed vertically or are randomly attached to an infusion pole. Our findings suggest that the arrangement of the pumps should be carefully considered, and that infusion pumps should be secured at the same position relative to the level of the patient. Since the same phenomenon described here can also occur when the patient is raised or lowered, changes in bed position should be considered, and also during transport of patients receiving catecholamine infusions.

The effects of infusion line compliance and syringe compliance on drug flow during vertical displacement of a syringe pump have been the subject of several recent reports. ${ }^{5-9}$ According to these reports, the compliance of the circuit of the syringe pump affects the flow when the pump is moved vertically. This may be due to various potential causes within the $i v$ setup: 


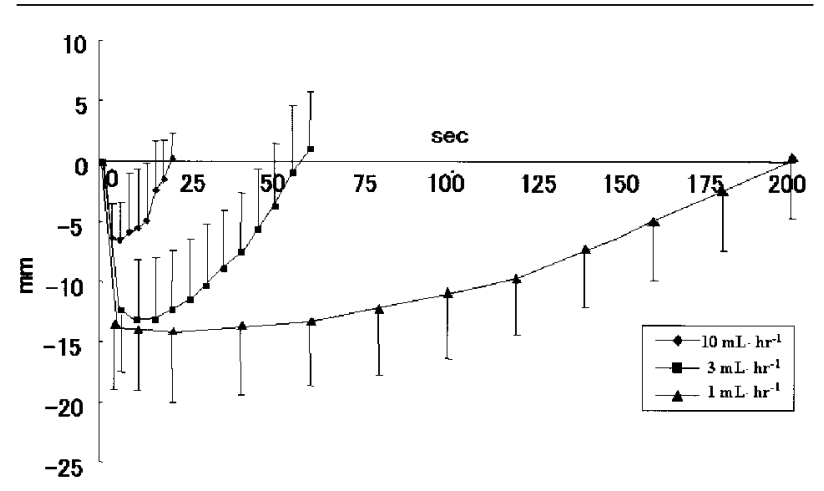

FIGURE 2 Distance of oil bubble movement when the syringe pump was moved downwards $50 \mathrm{~cm}$ vertically. Data are shown as mean $\pm \mathrm{SD}(n=17)$.

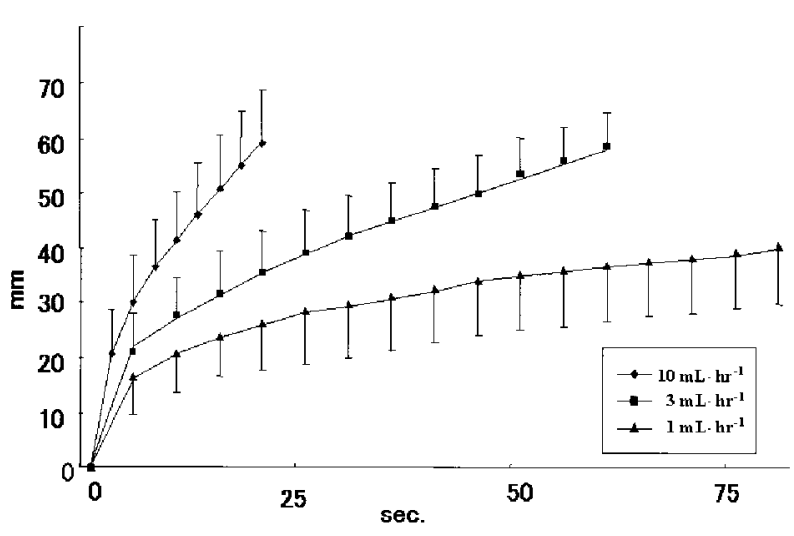

FIGURE 3 Distance of oil bubble movement when the syringe pump was raised $50 \mathrm{~cm}$ vertically.

Data are shown as mean \pm SD $(n=17)$.

the type of infusion pump, ${ }^{6,10}$ syringe variation with design and size, plunger position, ${ }^{11}$ the pressure-sensing disc, tubing length and stiffness, and the presence of an additional infusion line pressure transducer and the syringe pump itself. The most compliant part of the infusion system is supposed to be the syringe plunger, because it is usually made of soft materials, such as rubber. In the present study, the IP of the circuit system significantly increased with downward movement, and decreased with upward movement of the pump. However, the absolute change was similar for both directions of movement, regardless of the scheduled infusion rate. We therefore postulate that when the line IP of the circuit changes, the internal volume of the circuit might increase or decrease. This kind of phenomenon might affect the actual flow from the syringe pump, and we suggest that the use of a lower compliance circuit is appropriate for the management of critically ill patients. There are some reports of pumps improved to minimize such phenomenon. Weiss et al. reported the advantages of microvolumetric infusion pump (MVIP) prototype using a non-compliant microsyringe. They reported that the novel MVIP concept has eliminated most problems during vertical pump displacement. ${ }^{12}$ Neff $e t$ al. reported a reduced gravimetric influence of the Panomat ${ }^{\circledR}$ P-10 (Disetronic Medical Systems AG, Burgdorf, Switzerland) micro-volumetric infusion pump during vertical pump displacement, which was designed especially for microinfusion. ${ }^{13}$ Although 50$\mathrm{mL}$ syringes are commonly used when administering catecholamines, we chose $20-\mathrm{mL}$ syringes, which are of relatively low compliance. We use $20-\mathrm{mL}$ syringes in caring for neonates to improve accuracy of drug delivery when infusing catecholamines. ${ }^{2,5}$ Even with these low-compliant syringes, significant changes of flow were observed in the present study.

We note several limitations of the present experiments. First, in our pilot study, we tried several methods for measurement of flow from the syringe pump in vitro. We first performed reliability tests using an oil bubble and an air bubble to measure the actual flow from the syringe pump. The flow from the syringe pump using an oil bubble was $2.6 \%$ greater than that of the flow setting at $1 \mathrm{~mL} \cdot \mathrm{hr}^{-1}, 25.8 \%$ less than the flow setting at $3 \mathrm{~mL} \cdot \mathrm{hr}^{-1}$, and $26.2 \%$ less in the 10 $\mathrm{mL} \cdot \mathrm{hr}^{-1}$ group. Although the data using an air bubble were more accurate than those obtained using oil bubble movement at settings of $3 \mathrm{~mL} \cdot \mathrm{hr}^{-1}$ and 10 $\mathrm{mL} \cdot \mathrm{hr}^{-1}$, the air bubble was also more likely to break spontaneously, especially at the high flow rate. We viewed that it was too difficult to correct the data using an air bubble, and therefore decided to use the oil bubble method.

Second, the SET was supposed to be relatively compliant, and in the circuit we used an extra transducer to record circuit pressure, which might have affected our results. However, as we used the same system in all experiments, the percent differences would not have been altered.

Third, the experiments were performed at relatively high flow rates, compared to those used clinically. Altered infusion rates with vertical displacement may be of even greater relative importance at low flow rates, as often used in the pediatric and neonatal intensive care unit settings. ${ }^{7}$ 


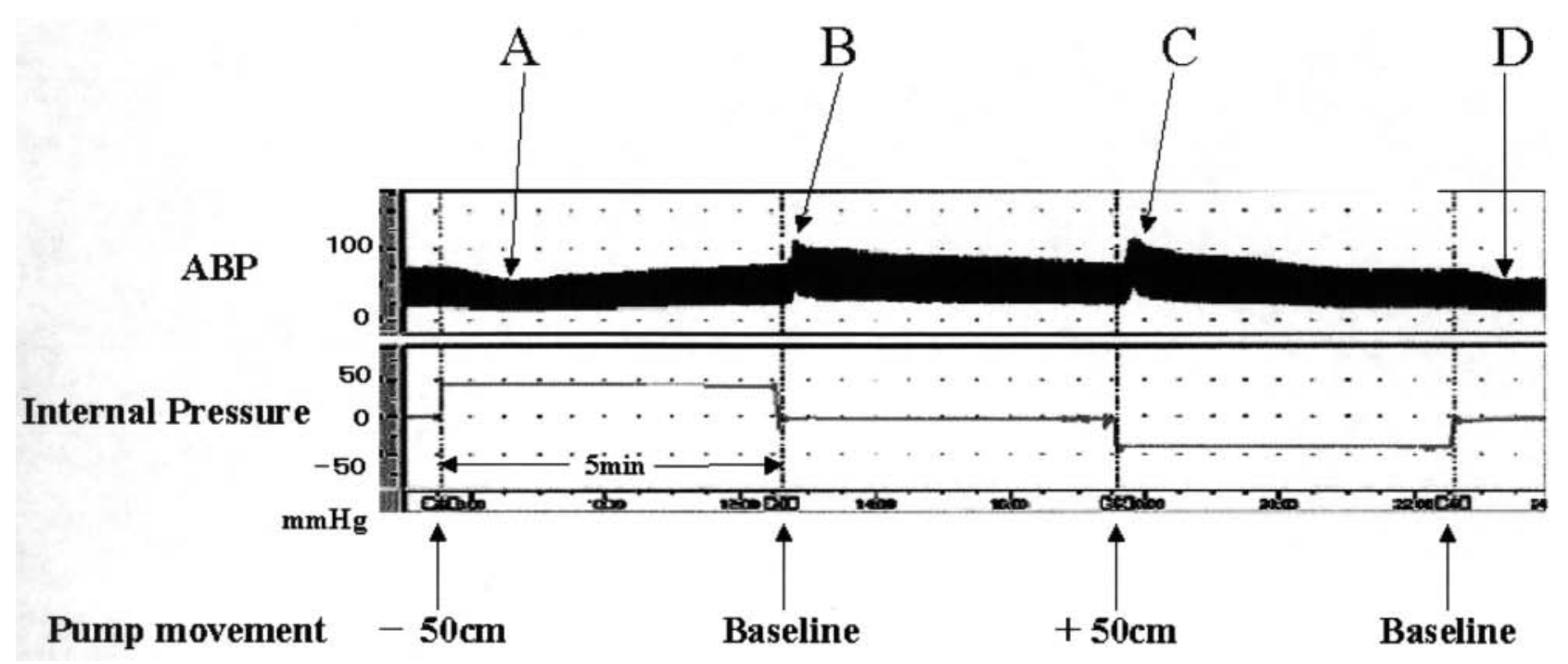

FIGURE 4 An example of hemodynamic changes and IP of the circuit. Norepinephrine was infused continuously at $3 \mu \mathrm{g} \cdot \mathrm{kg}^{-1} \cdot \mathrm{min}^{-1}$. $\mathrm{ABP}=$ arterial blood pressure; $\mathrm{IP}=$ internal pressure of the circuit of the syringe pump; $\mathrm{A}, \mathrm{D}$ : ABP decreased following a $50 \mathrm{~cm}$ downward displacement of the syringe pump. B, C: ABP increased following a $50 \mathrm{~cm}$ upward displacement of the syringe pump. Following downward movement of the syringe pump, line internal pressure (IP) increased and the blood pressure decreased (A). Line IP decreased following upward movement of the syringe pump, and the blood pressure increased rapidly (B, C). About 20 to 30 sec after the return of the syringe pump to baseline elevation, the systolic blood pressure decreased transiently $(\mathrm{D})$. Internal pressure changes were the same during downward movement and the return to baseline elevation, as during upward movement and the return to baseline elevation.

Fourth, we used a single pump from a single manufacturer, so the results of the study may have limited general application, and we cannot exclude the possibility of a design flaw of at least this particular pump. ${ }^{9}$ However, the aim of our study is not to demonstrate the differences between different pumps, but to demonstrate the general phenomenon. Kern et al. reported on three different pumps from three manufacturers, and found that the flow rates from each syringe pump was affected by vertical displacement. ${ }^{l}$

In conclusion, vertical displacement of syringe pumps may alter flow output due to change of line IP, and blood pressure can be affected by pump movement during NE infusion. We recommend that lines of relatively low compliance should be used when administering catecholamines and while transporting critically ill patients, and vertical pump displacement should be avoided to ensure accurate and stable flow delivery.

\section{References}

1 Kern H, Kuring A, Redlich U, et al. Downward movement of syringe pumps reduces syringe output. Br J Anaesth 2001; 86: 828-31.
2 Neff TA, Fischer JE, Schulz G, Baenziger O, Weiss M. Infusion pump performance with vertical displacement: effect of syringe pump and assembly type. Intensive Care Med 2001; 27: 287-91.

3 Russel GB, Myers JL, Kofke WA. Care of the cardiac surgical patient: the first 24 hours postoperatively. In: Hensley FA, Martin DE (Eds). The Practice of Cardiac Anesthesia. Boston: Little Brown; 1990: 289-321.

4 Sato S, Suzuki A, Nakajima $\Upsilon$, Iwamoto T, Bito H, Miyabe M. S-nitroso-N-acetylpenicillamine (SNAP) during hemorrhagic shock improves mortality as a result of recovery from vascular hyporeactivity. Anesth Analg 2000; 90: 362-8.

5 Weiss $M$, Bänziger $O, \operatorname{Neff} T$, Fanconi S. Influence of infusion line compliance on drug delivery rate during acute line loop formation. Intensive Care Med 2000; 26: 776-9.

6 Weiss M, Fischer J, Neff T, Baenziger O. The effects of syringe plunger design on drug delivery during vertical displacement of syringe pumps. Anaesthesia 2000; 55: 1094-8.

7 Weiss M, Hug MI, Neff T, Fischer J. Syringe size and flow rate affect drug delivery from syringe pumps. Can J Anesth 2000; 47: 1031-5. 
8 Lönnqvist PA. How continuous are continuous drug infusions? Intensive Care Med 2000; 26: 660-1.

9 Lönnqvist PA, Löfqvist B. Design flaw can convert commercially available continuous syringe pumps to intermittent bolus injectors. Intensive Care Med 1997; 23: 998-1001.

10 Klem SA, Farrington JM, Leff RD. Influence of infusion pump operation and flow rate on hemodynamic stability during epinephrine infusion. Crit Care Med 1993; $21:$ 1213-7.

11 Rooke GA, Bowdle TA. Syringe pumps for infusion of vasoactive drugs: mechanical idiosyncrasies and recommended operating procedures. Anesth Analg 1994; 78: 150-6.

12 Weiss M, Gerbe S, Füchslin RM, Neff TA. Accurate continuous drug delivery at low infusion rate with a novel microvolumetric infusion pump (MVIP): pump design, evaluation and comparison to the current standard. Anaesthesia, 2004; 59: 1133-7.

13 Neff TA, Fellmann C, Fuechslin RM, Gerber AC, Weiss $M$. The Panomat ${ }^{\circledR}$ P-10 micro-volumetric infusion pump is suitable for continuous drug administration at minimal flow rates. Can J Anesth 2002; 49: 1048-52. 